\title{
Stereotactic cyst aspiration directly followed by Gamma Knife radiosurgery for large cystic brain metastases
}

\author{
Zjiwar H. A. Sadik ${ }^{1,2,3}$ • Patrick E. J. Hanssens ${ }^{1}$ • Jeroen B. Verheul ${ }^{1,2} \cdot$ Hilko Ardon $^{2} \cdot$ Suan Te Lie ${ }^{1,2} \cdot$ Bram van \\ der Pol ${ }^{1,2} \cdot$ Guus N. Beute ${ }^{1,2} \cdot$ Ruth E. M. Fleischeuer ${ }^{4} \cdot$ Sieger Leenstra $^{3}$
}

Received: 22 October 2019 / Accepted: 19 February 2020

(C) Springer-Verlag GmbH Austria, part of Springer Nature 2020

\begin{abstract}
Background Gamma Knife radiosurgery (GKRS) has been proven to be a successful primary treatment for metastatic brain tumors (BM). BM can come in cystic lesions and are often too large for GKRS. An alternative approach to treat cystic BM is stereotactic cyst aspiration (SCA) for volume reduction, making it suitable for GKRS afterwards.

Objective Our objective is evaluation of volumetric reduction after SCA, tumor control, and complications after SCA directly followed by GKRS.

Methods We performed a retrospective analysis of all patients who underwent SCA directly followed by GKRS at the Gamma Knife Center of the Elisabeth-Tweesteden Hospital in Tilburg between 2002 and 2015. In total, 54 patients had undergone this combined approach. Two patients were excluded because of prior intracranial treatment. The other 52 patients were included for analysis.

Results SCA resulted in a mean volumetric reduction of 56.5\% (range 5.50-87.00\%). In 83.6\% of the tumors (46 tumors), SCA led to sufficient volumetric reduction making GKRS possible. The overall local tumor control (OLTC) of the aspirated lesions post-GKRS was $60.9 \%$ (28 out of 46 tumors). Median progression-free survival (PFS) and overall survival (OS) for all patients were 3 (range 5 days-14 months) and 12 months (range 5 days-58 months), respectively. Leptomeningeal disease was reported in $5(9.6 \%)$ cases. Conclusion SCA directly followed by GKRS is an effective and time-efficient treatment for large cystic BM in selected patients in which surgery is contraindicated and those with deeply located lesions.
\end{abstract}

Keywords Stereotactic cyst aspiration · Gamma Knife radiosurgery $\cdot$ Cystic brain metastases · Ommaya reservoir

Portions of this work were presented as an oral presentation at the 18th Leksell Gamma Knife Society Meeting, Amsterdam, The Netherlands, May 15-19, 2016.

\begin{tabular}{|c|c|c|}
\hline This article is part of the Topical Collection on Brain Tumors & & \\
\hline $\begin{array}{l}\triangle \text { Zjiwar H. A. Sadik } \\
\text { s_shibie@ @otmail.com }\end{array}$ & & $\begin{array}{l}\text { Ruth E. M. Fleischeuer } \\
\text { r.fleischeuer@etz.nl }\end{array}$ \\
\hline $\begin{array}{l}\text { Patrick E. J. Hanssens } \\
\text { p.hanssens@ etz.l }\end{array}$ & & $\begin{array}{l}\text { Sieger Leenstra } \\
\text { s.leenstra@erasmusmc.nl }\end{array}$ \\
\hline $\begin{array}{l}\text { Jeroen B. Verheul } \\
\text { j.verheul@ etz.nl }\end{array}$ & 1 & Gamma Knife Center, Elisabeth-Tweesteden Hospital, \\
\hline $\begin{array}{l}\text { Hilko Ardon } \\
\text { h.ardon@etz.nl }\end{array}$ & & Hilvarenbeekseweg 60, 5022 GC Tilburg, The Netherlands \\
\hline $\begin{array}{l}\text { Suan Te Lie } \\
\text { s.lie@etz.nl }\end{array}$ & 2 & $\begin{array}{l}\text { Department of Neurosurgery, Elisabeth-Tweesteden Hospital, } \\
\text { Hilvarenbeekseweg 60, } 5022 \text { GC Tilburg, The Netherlands }\end{array}$ \\
\hline $\begin{array}{l}\text { Bram van der Pol } \\
\text { b.vanderpol@etz.nl }\end{array}$ & 3 & $\begin{array}{l}\text { Department of Neurosurgery, Erasmus Medical Center, Doctor } \\
\text { Molewaterplein 40, } 3015 \text { GD Rotterdam, The Netherlands }\end{array}$ \\
\hline $\begin{array}{l}\text { Guus N. Beute } \\
\text { g.beute@etz.nl }\end{array}$ & 4 & $\begin{array}{l}\text { Department of Pathology, Elisabeth-Tweesteden Hospital, } \\
\text { Hilvarenbeekseweg } 60,5022 \text { GC Tilburg, The Netherlands }\end{array}$ \\
\hline
\end{tabular}




\section{Introduction}

The incidence of brain metastasis (BM) in cancer patients ranges between 20 and 40\% [16, 17]. Gamma Knife radiosurgery (GKRS) has been proven to be a successful primary treatment for metastatic brain tumors. On the other hand, GKRS has its own limitations. It is not suitable for large tumors, especially for tumors $>3 \mathrm{~cm}$ in diameter $[6,8]$. In case of large cystic metastasis, surgery is the first choice of treatment for these metastases. However, surgery may be contraindicated in some patients because of deep and eloquent cyst location, important co-morbidity, advanced age, and patient preference. An alternative approach is stereotactic cyst aspiration (SCA) to reduce the volume, making it suitable for GKRS afterwards. In this study, we describe a patient cohort, in which SCA is directly followed by GKRS on the same day. Our objective is evaluation of volumetric reduction after SCA, tumor control, and complications after reducing cyst aspiration followed by GKRS.

\section{Methods and materials}

Between June 10, 2002, and March 31, 2015, a total of 2842 procedures were performed at our center for patients with BM. Fifty-four of these procedures were planned for upfront SCA followed by GKRS on the same day for 57 large cystic metastases. The diagnosis was based on MRI findings. Pre- and post-treatment clinical characteristics were reviewed. We included all patients who never had any prior intracranial treatment and had a minimal cyst volume of $9 \mathrm{cc}$. Two patients were excluded because of previous intracranial treatment (one GKRS; one resection followed by craniospinal radiotherapy). The preoperative physical state was scored according to the ASA (American Society of Anesthesiologists) grading system. All patients included were ASA IV. A total of 52 patients were included with 20 of these patients having solitary cystic metastases and 32 patients with additional lesions (cystic or non-cystic). Two of the 32 patients had only 2 cystic metastases (both lesions underwent SCA), and a third patient had 2 cystic lesions (both underwent SCA) with multiple non-cystic lesions. Eventually, a total of 55 large cystic metastases were planned for SCA followed by GKRS on the same day. Cystic fluid aspirated during SCA procedure was sent for histopathological evaluation.

All cases were retrospectively analyzed. Therefore, there was no need for ethical approval by the ethics committee. All patients were classified according to the recursive partitioning analysis (RPA) classification system of the Radiation Therapy Oncology Group (RTOG) [18]. The included patients consisted of 20 males and 32 female, with a median age of 61 (range 36-83 years). The most frequent primary tumor was non-small cell lung cancer (NSCLC) followed by breast cancer (BC) with the majority of the BM located in the supratentorial region. Other pre-treatment patient characteristics are summarized in Table 1. Pre- and post-SCA tumor volume was measured with the Leksell GammaPlan Software (Elekta).

\section{Treatment procedure}

The SCA was performed under local anesthesia in the operating theater. Prior to the SCA, the application of the Leksell

Table 1 Pre-treatment patients characteristics

\begin{tabular}{|c|c|c|c|}
\hline Characteristics & $\begin{array}{l}\text { No. of } \\
\text { patient }\end{array}$ & Median & Range \\
\hline \multicolumn{4}{|l|}{ Gender } \\
\hline Male & 20 & & \\
\hline Female & 32 & & \\
\hline Age (years) & & 61 & $36-83$ \\
\hline KPS sore & & 80 & $50-100$ \\
\hline \multicolumn{4}{|l|}{ RPA classification } \\
\hline Class 1 & 11 & & \\
\hline Class 2 & 34 & & \\
\hline Class 3 & 7 & & \\
\hline \multicolumn{4}{|l|}{ Primary tumor } \\
\hline NSCLC & 34 & & \\
\hline Breast cancer & 7 & & \\
\hline Colorectal cancer & 4 & & \\
\hline Oesophageal cancer & 1 & & \\
\hline Endometrium cancer & 1 & & \\
\hline Ovarian cancer & 1 & & \\
\hline Bladder cancer & 1 & & \\
\hline Parotid cancer & 1 & & \\
\hline PTU & 2 & & \\
\hline \multicolumn{4}{|l|}{ Location of cystic lesions } \\
\hline Supratentorial & 36 & & \\
\hline Infratentorial & 19 & & \\
\hline Solitary cystic lesions & 20 & & \\
\hline Multiple cystic and non-cystic lesions & 32 & & \\
\hline Number of metastases & & 2 & $1-9$ \\
\hline 1 & 20 & & \\
\hline 2 & 11 & & \\
\hline 3 & 10 & & \\
\hline$\geq 4$ & 11 & & \\
\hline Pre-aspiration tumor volume (cc) & & 26.9 & $9.97-111.50$ \\
\hline Synchronous metastasis & 15 & & \\
\hline Metachronous metastasis & 35 & & \\
\hline PTU & 2 & & \\
\hline
\end{tabular}

$N S C L C$, non-small cell carcinoma; $K P S$, Karnofsky performance status; $R P A$, recursive partitioning analysis; $P T U$, primary tumor unknown 
stereotactic frame was performed using a local anesthetic solution. Following frame placement, MRI was obtained, and the patient was transferred to the operating room. This SCA procedure is navigation-based whereby the biopsy needle is fixed on a stereotactic biopsy device attached to the Leksell stereotactic frame. The path for the aspiration needle was determined using the Leksell Surgiplan $®$ software. Immediately after SCA, the patients were transferred to the Gamma Knife Center for subsequent radiosurgery.

The GKRS procedure was performed using the Leksell Gamma Knife 4C, before 2009, and Leksell Gamma Knife Perfexion thereafter. Following SCA, high-resolution stereotactic MRI (1.5 Tesla) was performed for treatment planning. Pre- and post-contrast (triple-dose gadolinium) T1 weighted axial images were obtained with a slice thickness of $1.5 \mathrm{~mm}$. Stereotactic radiosurgery and dose planning was performed by a team of a neurosurgeon, radiation oncologist, and medical physicist. The target was defined as the contrast enhancing lesions on the planning MRI. The median number of metastases treated with GKRS was 2 (range 1-9) with a mean/ median tumor volume of $6.5 \mathrm{cc} / 6.2 \mathrm{cc}$ (range $0.001-$ $43.504 \mathrm{cc}$ ). The prescribed dose ranged between 20 and 25 Gy (median 20 Gy), depending on the size and location of the tumor. The dose was prescribed to the isodoseline covering $99 \%$ of the target.

After completion of the treatment, patients were admitted to the ward for 1-day observation. After GKRS, follow-up (FU) including MRIs was performed at 6 weeks, 3 months after treatment, and thereafter every 3 months as long as clinically meaningful. Treatment-associated complications were documented.

\section{Definitions}

Overall intracranial tumor control: Freedom from any kind of progression (reaccumulation of cystic fluid, and/or local tumoral tissue progression, and/or occurrence of distant lesions) until the end of FU.

Overall local tumor control of aspirated lesions: This includes freedom from any local progression (reaccumulation of cystic fluid and/or tumoral tissue progression).
Overall local tumoral tissue control of aspirated lesions: This includes freedom from tumoral tissue progression but does not include freedom from reaccumulation of cystic fluid.

\section{Statistical analysis}

All statistical analyses were performed using IBM SPSS statistics version 23. Kaplan-Meier curve was plotted to determine tumor control, overall survival, and progression-free survival.

\section{Results}

\section{Volumetric reduction after SCA}

Prior to SCA, the mean/median tumor volume was $35.3 \mathrm{cc} /$ $31.3 \mathrm{cc}$ (range $10.0-111.5 \mathrm{cc}$ ). The mean/median post-SCA volume was $14.2 \mathrm{cc} / 12.7 \mathrm{cc}$ (range $4.2-47.0 \mathrm{cc}$ ). This resulted in a mean volumetric reduction of $56.4 \%$ (range $5.5-87.0 \%$ ) (Fig. 1). In $83.6 \%$ of the tumors (46 tumors, mean/median volume of $11.2 \mathrm{cc} / 9.3 \mathrm{cc}$, range $4.2-15.0 \mathrm{cc}$ ), SCA led to sufficient volumetric reduction making it possible to undergo GKRS. The cutoff point for undergoing GKRS was $15 \mathrm{cc}$ (equivalent to the volume of a $3-\mathrm{cm}$ diameter sphere). The median PD was 20 (range 20-25 Gy).

Those patients not eligible for GKRS after SCA underwent a second stage craniotomy, radiation therapy, or a combination of both (Table 2).

\section{Complications after SCA}

Complications occurred in 3 patients $(5.8 \%)$ which resulted in death of 2 patients. One died due to pneumocephalus and another due to epidural bleeding. The third patient developed a cerebral vascular accident (CVA) after 1 month of FU. This third patient stopped its anticoagulant therapy (acetylsalicylic acid) before the procedure and restarted it after 1 week. No seeding occurred in any patients during FU.
Fig. 1 Effect cyst aspiration on tumor volume

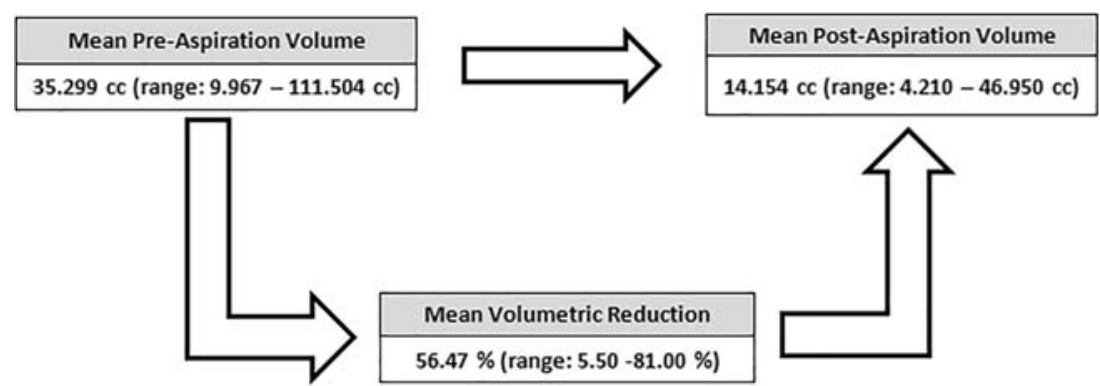


Table 2 Second treatment after failed SCA and tumoral tissue progression

\begin{tabular}{ll}
\hline Second treatment & No. of patients \\
Second treatment after failed SCA & \\
\hline Craniotomy & 3 \\
RT & 3 \\
Craniotomy + postoperative WBRT & 1 \\
Craniotomy + postoperative RT & 1 \\
Second treatment after tumoral tissue progression & \\
SCA + ORP followed by GKRS & 4 \\
GKRS & 7 \\
\hline
\end{tabular}

$R T$, radiotherapy; $W B R T$, whole brain radiotherapy; $S C A$, stereotactic cyst aspiration; ORP, Ommaya reservoir placement; GKRS, Gamma Knife radiosurgery

\section{Tumor control by GKRS}

GKRS could take place in $46(83.6 \%)$ cystic tumors. After GKRS, the overall intracranial tumor control was $53.3 \%$ (24 out of 45 patients).

The overall local tumor control of the aspirated cystic lesions after GKRS was $60.9 \%$ ( 28 out of 46 tumors). Seven (15.2\%) of these lesions demonstrated only reaccumulation of cystic fluid, four (8.7\%) demonstrated reaccumulation of cystic fluid in combination with tumoral tissue progression, and seven $(15.2 \%)$ demonstrated only tumoral tissue progression. All these patients received additional treatment. Thus, the overall local tumoral tissue control of aspirated lesions was $76.1 \%$ (35 out 46 tumors). No significant difference was shown in those who received a PD of $>20$ (log rank test; $p=0.54)$. When there only was reaccumulation of cystic fluid and no local tumor progression, patients received salvage treatment in the form of a second SCA (4 patients) alone or SCA with Ommaya reservoir (3 patients) placement (ORP). In case of tumoral tissue progression, patients received antitumoral therapy (Table 2). The overall local tumor control of the small non-aspirated lesions was $100 \%$. Distant progression occurred in 15 (29\%) patients after a median FU time of 7 months (range 1-36 months). Seeding did not occur in any of the patients. Leptomeningeal disease was reported in 5 (9.6\%) cases after a median FU time of 6 months (range 37 months). No GKRS-related complications occurred. Kaplan-Meier curve of the local tumor control of the aspirated lesions is shown in Fig. 2.

\section{Adverse events}

Adverse events were scored according to the CTCAE (CTCM) version 4.0. Forty patients (77\%) had no adverse events. Frame-related swelling occurred in $9.6 \%$ (5 out of 52) of the patients within a median time of 10 days. Headache (grade I) occurred in 3 patients (5.8\%) and focal alopecia (grade I) in 4 patients $(7.6 \%)$. No serious adverse events were noted after GKRS.

\section{Survival}

A total of 43 patients died during FU. Nine patients (20.9\%) died due to intracranial disease, $22(51.2 \%)$ due to extracranial disease, and 12 (27.9\%) due to intra- and extracranial disease. Median progression-free survival (PFS) and overall survival (OS) for all patients were 3 (range 5 days-14 months) and 12 months (range 5 days-58 months), respectively (Fig. 2).

\section{Neurology}

Pre-SCA symptoms were headache (20 patients, 38\%), focal motor deficit (16 patients, $31 \%$ ), and ataxia (16 patients, $31 \%$ ). Improvement of symptoms occurred in all patients $(100 \%)$ immediately after the SCA. The neurological control (freedom from neurological progression) was $100 \%, 77 \%$, $73 \%, 70 \%$, and $54 \%$ at $2,4,6,8$, and 10 months of FU, respectively. At a median FU time of 12 months, the neurological control had dropped to $34 \%$.

\section{Histopathology}

The nature of the aspirated content was analyzed by the pathology department. In 37 cases, only the cyst fluid was aspirated and in 18 cases the cyst aspiration was accompanied with biopsy of the cyst wall. In $78 \%$ of the cases that underwent cyst aspiration in combination with biopsy, the diagnosis could be confirmed versus $54 \%$ in those that only underwent cyst aspiration (Table 3).

Two types of fluids were obtained in patients undergoing the stereotactic aspiration. These types of fluid were yellowish turbid and yellowish transparent. The turbid fluid contained much more tumor cells, necrotic cells, and macrophages in comparison with the transparent fluid (Table 3).

\section{Discussion}

Gamma Knife radiosurgery has established itself as a powerful tool for the treatment of BM. However, BM can come in cystic lesions often too large for GKRS. Another important aspect is that cystic BM tends to have a less good reaction to radiosurgery $[2,14]$. Conventionally, single large cystic BM has been regarded as an indication for surgery since it can provide rapid relief of neurological symptoms caused by the mass effect [2, 21]. However, if these lesions are located deep within the brain or in eloquent areas, surgery may result in severe neurological deficit. In addition, patients in poor general condition or with multiple lesions are not suitable for surgery. An alternative approach is to make these tumors 
Fig. 2 a Kaplan-Meier curve of the local tumor control. b

Kaplan-Meier curve of the progression-free survival. c

Kaplan-Meier curve of the over-

all survival
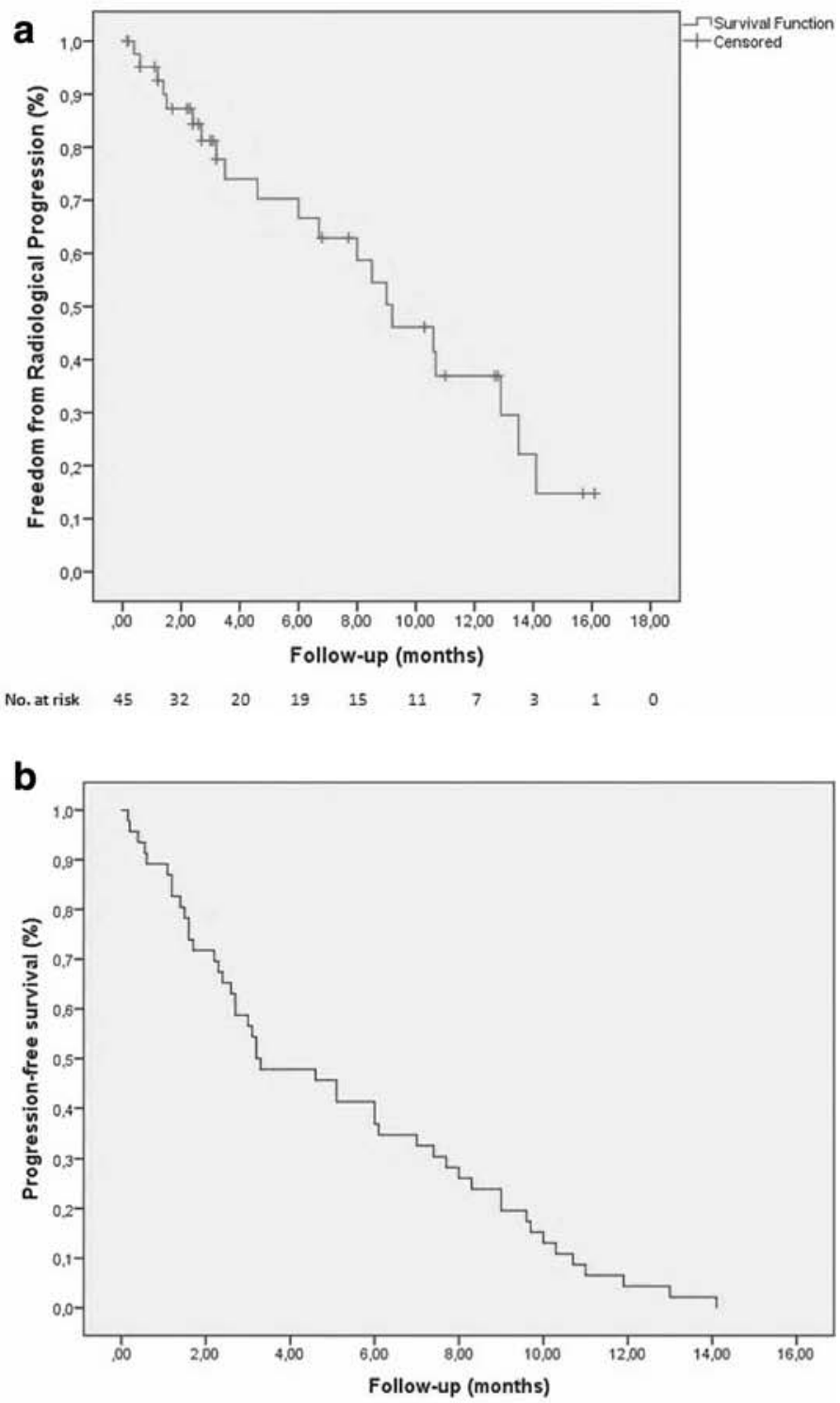

$\begin{array}{lllllllll}\text { No. at risk } & 45 & 33 & 22 & 18 & 12 & 6 & 2 & 1\end{array}$

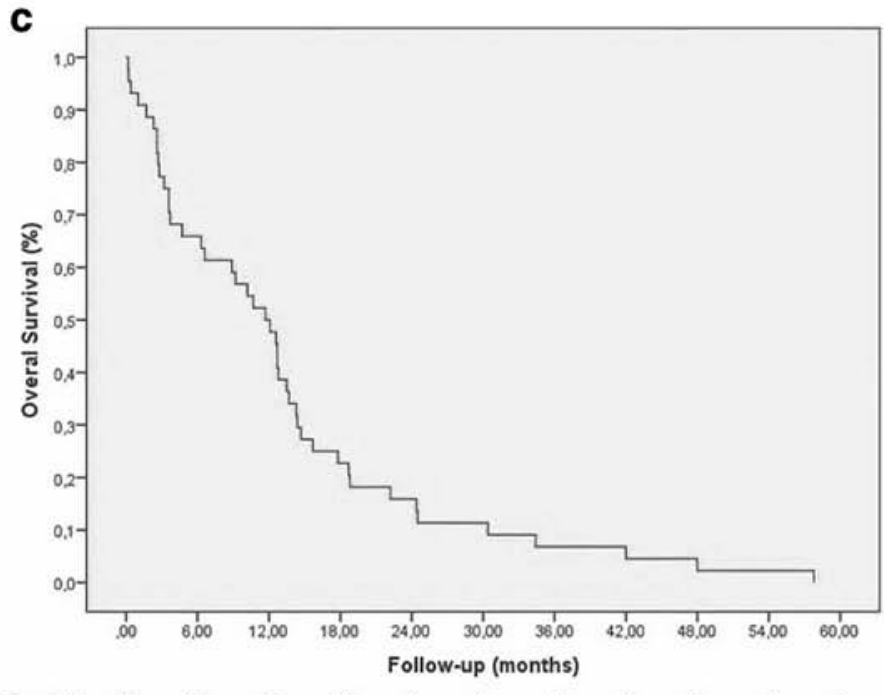

No. at risk $\begin{array}{llll}45 & 29 & 22 & 10\end{array}$ 
Table 3 Pathological evaluation of the aspirated fluid content

\begin{tabular}{lll}
\hline Procedure & No. of tumors & $\begin{array}{l}\text { No. of PA confirmation } \\
\text { of primary tumor }\end{array}$ \\
\hline $\begin{array}{l}\text { SCA alone } \\
\text { Type of cells }\end{array}$ & $20(54 \%)$ \\
Tumor cells & $20(54 \%)$ & \\
Macrophages & $18(49 \%)$ & \\
Histiocytes & $2(5 \%)$ & \\
Necrotic cells & $16(43 \%)$ & \\
SCA + biopsy & 18 \\
Type of cells & \\
Tumor cells & $14(78 \%)$ \\
Macrophages & $3(17 \%)$ \\
Histiocytes & $2(11 \%)$ \\
Necrotic cells & $12(67 \%)$ \\
Fluid type & \\
Orange/yellowish turbid & 31 \\
Tumor cells & $25(80 \%)$ \\
Macrophages & $13(42 \%)$ \\
Histiocytes & $2(6 \%)$ \\
Necrotic cells & $20(65 \%)$ \\
Orange/yellowish transparent & 14 \\
Tumor cells & $7(50 \%)$ \\
Macrophages & $3(21 \%)$ \\
Histiocytes & $2(14 \%)$ \\
Necrotic cells & $8(57 \%)$ \\
\hline
\end{tabular}

$S C A$, stereotactic cyst aspiration

suitable for GKRS by reducing the volume via SCA. Combination of these two procedures into one treatment makes it possible to treat large cystic metastases with GKRS in patients not fit for craniotomy. Thus, we designed a sequence of procedures in which SCA is immediately followed by GKRS on the same day. Using the same Leksell stereotactic frame for both procedures allows a seamless flow from SCA to GKRS in 1 day, reducing the physical and psychological burden for the patient. Another advantage of this 1-day approach is to minimize the time window within which the cyst reaccumulates fluid and thus avoiding the need for continuous aspiration through an Ommaya reservoir (OR). The goal of this type of treatment is to obtain mass reduction with a relatively small surgical procedure and thus relieve of neurologic symptoms in combination with radiation-induced cell death without damaging surrounding neuronal tissue.

SCA is an important first procedure. The volumetric decrease will determine whether a patient is eligible for GKRS. The cutoff point was set at $15 \mathrm{cc}$ after SCA which is equivalent to the volume of a $3-\mathrm{cm}$ diameter sphere. This is in line with others setting a cutoff point between 16.0 and $16.6 \mathrm{cc}[3,19]$.
In this study, SCA led to $83.6 \%$ of the tumors (46 tumors) to sufficient volumetric reduction making it possible to undergo GKRS.

The mean volumetric decrease was $56.5 \%$ after SCA which is within the range of other studies reporting a mean volumetric decrease of $47.8-77.9 \%[2,3,5,15]$ after SCA. A great advantage of cyst aspiration is acute symptomatic relief due to mass reduction. Immediate improvement of symptoms occurred in all patients (100\%) following drainage. This immediate neurological improvement after SCA was also reported by others $[9,13,15,19]$.

An important question is whether an OR placement during SCA can have additional value since reaccumulation of cystic fluid after GKRS occurred in $23.9 \%$ of the lesions (11 out of 46 tumors).

Park et al. reported a mean volumetric decrease of $77.9 \%$ [15]. The reason for this high rate of reduction is because $48 \%$ of the lesions were treated with additional OR insertion after SCA. In 2006, Yamanaka et al. placed an OR during cyst aspiration followed by GKRS up to 60 days later [20]. This two-step approach may be more feasible for most centers but is more uncomfortable for patients since this treatment takes more time and may increase the risk of fluid reaccumulation during the waiting period. However, an advantage of ORP in addition to SCA is when during the GKRS planning MRI a tumor volume is seen still too large for GKRS one can undergo immediate additional subcutaneous cyst aspiration via the reservoir to obtain a sufficient reduction in volume. This approach of ORP during SCA is to be seriously considered in our center due to its practicality and since it can serve as an additional tool for sufficient reduction in volume prior and after GKRS in case of fluid reaccumulation without the need for a second surgical procedure. Thus, it can serve as tumor control and relieve of neurological symptoms. This may have prevented surgery in our patients not eligible for GKRS after SCA and in those needing a second SCA or ORP after GKRS (Table 2). However, ORP during SCA should only be considered for very large lesions following removal of clear-fluid content. In case of turbid fluid, the chance of the tube remaining patent is probably low.

Complications related to the SCA are relatively rare. Possible complications include hemorrhage, neurological deficits, seizures, and infections [10]. The mortality rate in large series has been less than $1 \%$, and the complication rates vary from $0-7 \%[1,10]$. This is in line with our study reporting a complication rate of $5.8 \%$. Unfortunately two patients died in this study due to SCA-related complications: one due to pneumocephalus and the other due to an epidural bleeding resulting in a mortality rate of $3.8 \%$. This is a high mortality rate and does not evoke enthusiasm. However, one should bear in mind that there is a selection bias since the study population are all ASA IV. These patients have a higher peri- and postoperative complication rate and thus a higher 
mortality risk. Another explanation is the relative small number of patients included in the study. Increasing the study population will result in a lower mortality rate.

There is a theoretical risk for tumor cell seeding along the aspiration needle tract. However, the incidence of seeding is poorly described in the literature after SCA. Seeding is mainly described in studies performing stereotactic needle biopsy. Karlsson et al. reported tumor cell seeding in $9 \%$ of the patients treated with GKRS for BM in whom biopsy specimens were obtained via stereotactic needle biopsy prior to the radiosurgical treatment [7]. In our study, seeding did not occur in any of the patients.

Tumor control is an important aspect of this treatment. The overall local tumor control of the aspirated cystic lesions after GKRS was $60.9 \%$, which is within the range of other studies reporting a tumor control of 54.2-91.7\% [2, 3, 5, 9, 15, 19, 20]. The local tumor progression was $39.1 \%$ which is in line with others reporting a local tumor progression of $8.3-41.4 \%$ $[2,3,5,9,15,19,20]$. Distant progression was $29 \%$ whereas others reported distant progression of $16.7-52.2 \%$ [2, 15, 19]. The mean tumor volume of the aspirated cystic lesions undergoing GKRS was $11.168 \mathrm{cc}$ (range $4.210-14.950 \mathrm{cc}$ ). The median PD was 20 Gy (range 20-25 Gy). Larger tumors received a lower dose (20 Gy). This may account for higher rates of tumor recurrence. Leptomeningeal disease was reported in $9.6 \%$ of the cases. Others observed leptomeningeal dissemination of $14.2 \%$ after GKRS [12]. Franzin et al. reported that $7.6 \%$ of the patients experienced radionecrosis after stereotactic aspiration followed by SCA of cystic BM [2]. In our study, no radiation necrosis was seen in any of the patients during FU.

Stereotactic radiotherapy (SRT) can be a good alternative option in patients with large cystic tumors after SCA. SRT can be used for optimizing radiation dose to large residual cystic tumors. Ikushima et al. reported a median survival of 4.3 months in patients undergoing SRT, which is far lower compared with those who underwent SRS (25.6 months) or surgery in combination with postoperative SRT (18.7 months) [4].

The overall median survival in this study was 12 months. Others reported similar median overall survival rates ranging from 6.8-19.5 months [2, 3, 5, 9, 15, 19, 20]. Tendulkar et al. reported a median survival of 8.7 months in those undergoing subtotal resection for single brain metastasis and 10.6 months after gross total resection (GTR) [18]. Although it is difficult to compare these results with ours, the results of GKRS after SCA of large cystic BM were as good as that of GTR. Therefore, SCA followed by GKRS could be a better treatment option instead of surgical resection for cystic tumors located in deep or eloquent areas within the brain. Another well-known treatment option is surgery followed by WBRT. In 2008, a randomized controlled trial showed that this treatment resulted in a median survival time of 9.5 months which is comparable with our study [11].
Histopathological analysis was done on the aspirated cystic fluid. The turbid fluid contained, as expected, much more tumor cells, necrotic cells, and macrophages compared with the transparent fluid. Cyst aspiration in combination with biopsy of the cyst wall resulted in $78 \%$ of the case confirmation of the histopathological diagnosis compared with $54 \%$ in those that only underwent cyst aspiration. To increase the chance of histopathological confirmation of the diagnosis, cyst aspiration in combination of biopsy of the cyst wall is advised.

\section{Study limitations}

This is a single center retrospective study with a relatively small number of patients and is therefore subjected to biases (selection bias and treatment bias) and limitations. Major limitations are non-protocolized treatment regimens. All patients received systemic treatment prior to GKRS. The treatment included the use of chemotherapeutic agents, and heterogeneity in primary tumors. Therefore, the group we present is heterogeneous which makes comparison to historical groups difficult.

\section{Conclusion}

This study shows that SCA results in sufficient volumetric decrease of cystic BM in a high percentage of the cases, making these lesions suitable for GKRS. Reduction of the volume permits higher radiation doses and is associated with lower risk of post-radiation complications. This 1-day aspiration followed by GKRS is less invasive than resection but should be used for selected patients whose overall condition is too poor to undergo microsurgery and in those with deeply located lesions or multiple lesions, since SCA can be associated with significant complications.

An Ommaya reservoir placement during SCA is recommended since it can serve as an additional tool to obtain sufficient volumetric decrease in case of fluid reaccumulation avoiding the need for a second surgical procedure.

\section{Compliance with ethical standards}

Conflict of interest The authors declare that they have no conflict of interest.

Ethical approval All procedures performed in studies involving human participants were in accordance with the ethical standards of the institutional and/or national research committee and with the 1964 Helsinki declaration and its later amendments or comparable ethical standards. This article does not contain any studies with human participants or animals performed by any of the authors.

Informed consent Informed consent was obtained from all individual participants included in the study. 


\section{References}

1. Bernstein M, Parrent AG (1994) Complications of CT-guided stereotactic biopsy of intra-axial brain lesions. J Neurosurg 81:165168. https://doi.org/10.3171/jns.1994.81.2.0165

2. Franzin A, Vimercati A, Picozzi P, Serra C, Snider S, Gioia L, Ferrari da Passano C, Bolognesi A, Giovanelli M (2008) Stereotactic drainage and Gamma Knife radiosurgery of cystic brain metastasis. J Neurosurg 109:259-267. https://doi.org/10. 3171/jns/2008/109/8/0259

3. Higuchi F, Kawamoto S, Abe Y, Kim P, Ueki K (2012) Effectiveness of a 1-day aspiration plus Gamma Knife surgery procedure for metastatic brain tumor with a cystic component. J Neurosurg 117(Suppl):17-22. https://doi.org/10.3171/2012.7. gks 121001

4. Ikushima H, Tokuuye K, Sumi M, Kagami Y, Murayama S, Ikeda H, Tanaka M, Oyama H, Shibui S, Nomura K (2000) Fractionated stereotactic radiotherapy of brain metastases from renal cell carcinoma. Int J Radiat Oncol Biol Phys 48:1389-1393. https://doi.org/ 10.1016/s0360-3016(00)00804-x

5. Jung TY, Kim IY, Jung S, Jang WY, Moon KS, Park SJ, Lim SH (2014) Alternative treatment of stereotactic cyst aspiration and radiosurgery for cystic brain metastases. Stereotact Funct Neurosurg 92:234-241. https://doi.org/10.1159/000362935

6. Kalkanis SN, Kondziolka D, Gaspar LE, Burri SH, Asher AL, Cobbs CS, Ammirati M, Robinson PD, Andrews DW, Loeffler JS, McDermott M, Mehta MP, Mikkelsen T, Olson JJ, Paleologos NA, Patchell RA, Ryken TC, Linskey ME (2010) The role of surgical resection in the management of newly diagnosed brain metastases: a systematic review and evidence-based clinical practice guideline. J Neuro-Oncol 96:33-43. https://doi.org/10.1007/ s11060-009-0061-8

7. Karlsson B, Ericson K, Kihlstrom L, Grane P (1997) Tumor seeding following stereotactic biopsy of brain metastases. Report of two cases. J Neurosurg 87:327-330. https://doi.org/10.3171/jns. 1997.87.2.0327

8. Linskey ME, Andrews DW, Asher AL, Burri SH, Kondziolka D, Robinson PD, Ammirati M, Cobbs CS, Gaspar LE, Loeffler JS, McDermott M, Mehta MP, Mikkelsen T, Olson JJ, Paleologos NA, Patchell RA, Ryken TC, Kalkanis SN (2010) The role of stereotactic radiosurgery in the management of patients with newly diagnosed brain metastases: a systematic review and evidencebased clinical practice guideline. J Neuro-Oncol 96:45-68. https:// doi.org/10.1007/s11060-009-0073-4

9. Liu X, Yu Q, Zhang Z, Zhang Y, Li Y, Liu D, Jia Q, Zheng L, Xu D (2012) Same-day stereotactic aspiration and Gamma Knife surgery for cystic intracranial tumors. J Neurosurg 117(Suppl):45-48. https://doi.org/10.3171/2012.7.gks121019

10. Lunsford LD, Martinez AJ (1984) Stereotactic exploration of the brain in the era of computed tomography. Surg Neurol 22:222-230

11. Muacevic A, Wowra B, Siefert A, Tonn JC, Steiger HJ, Kreth FW (2008) Microsurgery plus whole brain irradiation versus Gamma Knife surgery alone for treatment of single metastases to the brain: a randomized controlled multicentre phase III trial. J Neuro-Oncol 87:299-307. https://doi.org/10.1007/s11060-007-9510-4

12. Nakazaki K, Nishigaki M (2018) Evaluation of new lesions and symptoms after gamma knife radiosurgery for brain metastases: a retrospective cohort study. Acta Neurochir 160:1461-1471. https:// doi.org/10.1007/s00701-018-3524-x

13. Niranjan A, Witham T, Kondziolka D, Lunsford LD (2000) The role of stereotactic cyst aspiration for glial and metastatic brain tumors. Can J Neurol Sci 27:229-235

14. Pan HC, Sheehan J, Stroila M, Steiner M, Steiner L (2005) Gamma knife surgery for brain metastases from lung cancer. J Neurosurg 102(Suppl):128-133

15. Park WH, Jang IS, Kim CJ, Kwon DH (2009) Gamma knife radiosurgery after stereotactic aspiration for large cystic brain metastases. J Korean Neurosurg Soc 46:360-364. https://doi.org/10.3340/jkns. 2009.46.4.360

16. Patchell RA (2003) The management of brain metastases. Cancer Treat Rev 29:533-540

17. Patchell RA, Regine WF (2003) The rationale for adjuvant whole brain radiation therapy with radiosurgery in the treatment of single brain metastases. Technol Cancer Res Treat 2:111-115

18. Tendulkar RD, Liu SW, Barnett GH, Vogelbaum MA, Toms SA, Jin T, Suh JH (2006) RPA classification has prognostic significance for surgically resected single brain metastasis. Int J Radiat Oncol Biol Phys 66:810-817. https://doi.org/10.1016/j.ijrobp.2006.06.003

19. Wang H, Qi S, Dou C, Ju H, He Z, Ma Q (2016) Gamma Knife radiosurgery combined with stereotactic aspiration as an effective treatment method for large cystic brain metastases. Oncol Lett 12: 343-347. https://doi.org/10.3892/ol.2016.4603

20. Yamanaka Y, Shuto T, Kato Y, Okada T, Inomori S, Fujino H, Nagano H (2006) Ommaya reservoir placement followed by Gamma Knife surgery for large cystic metastatic brain tumors. J Neurosurg 105(Suppl):79-81. https://doi.org/10.3171/sup.2006. 105.7.79

21. Yoshida S, Morii K (2004) The role of surgery in the treatment of brain metastasis: a retrospective review. Acta Neurochir 146:767770. https://doi.org/10.1007/s00701-004-0228-1

Publisher's note Springer Nature remains neutral with regard to jurisdictional claims in published maps and institutional affiliations. 